The National Bureau of Standards ${ }^{1}$ was established by an act of Congress March 3, 1901. The Bureau's overall goal is to strengthen and advance the Nation's science and technology and facilitate their effective application for public benefit. To this end, the Bureau conducts research and provides: (1) a basis for the Nation's physical measurement system, (2) scientific and technological services for industry and government, (3) a technical basis for equity in trade, and (4) technical services to promote public safety. The Bureau consists of the Institute for Basic Standards, the Institute for Materials Research, the Institute for Applied Technology, the Center for Computer Sciences and Technology, and the Office for Information Programs.

THE INSTITUTE FOR BASIC STANDARDS provides the central basis within the United States of a complete and consistent system of physical measurement; coordinates that system with measurement systems of other nations; and furnishes essential services leading to accurate and uniform physical measurements throughout the Nation's scientific community, industry, and commerce. The Institute consists of a Center for Radiation Research, an Office of Measurement Services and the following divisions:

Applied Mathematics-Electricity-Heat-Mechanics-Optical Physics-Linac Radiation ${ }^{2}$ - Nuclear Radiation ${ }^{2}$ - Applied Radiation ${ }^{2}$ - Quantum Electronics 3 Electromagnetics ${ }^{3}$ - Time and Frequency ${ }^{3}$ - Laboratory Astrophysics ${ }^{3}$ - Cryogenics $^{3}$.

THE INSTITUTE FOR MATERIALS RESEARCH conducts materials research leading to improved methods of measurement, standards, and data on the properties of well-characterized materials needed by industry, commerce, educational institutions, and Government; provides advisory and research services to other Government agencies; and develops, produces, and distributes standard reference materials. The Institute consists of the Office of Standard Reference Materials and the following divisions:

Analytical Chemistry-Polymers-Metallurgy-Inorganic Materials-Reactor Radiation-Physical Chemistry.

THE INSTITUTE FOR APPLIED TECHNOLOGY provides technical services to promote the use of available technology and to facilitate technological innovation in industry and Government; cooperates with public and private organizations leading to the development of technological standards (including mandatory safety standards), codes and methods of test; and provides technical advice and services to Government agencies upon request. The Institute also monitors NBS engineering standards activities and provides liaison between NBS and national and international engineering standards bodies. The Institute consists of the following technical divisions and offices:

Engineering Standards Services-Weights and Measures-Flammable FabricsInvention and Innovation-Vehicle Systems Research-Product Evaluation Technology-Building Research-Electronic Technology-Technical AnalysisMeasurement Engineering.

THE CENTER FOR COMPUTER SCIENCES AND TECHNOLOGY conducts research and provides technical services designed to aid Government agencies in improving cost effectiveness in the conduct of their programs through the selection, acquisition, and effective utilization of automatic data processing equipment; and serves as the principal focus within the executive branch for the development of Federal standards for automatic data processing equipment, techniques, and computer languages. The Center consists of the following offices and divisions:

Information Processing Standards-Computer Information-Computer Services -Systems Development-Information Processing Technology.

THE OFFICE FOR INFORMATION PROGRAMS promotes optimum dissemination and accessibility of scientific information generated within NBS and other agencies of the Federal Government; promotes the development of the National Standard Reference Data System and a system of information analysis centers dealing with the broader aspects of the National Measurement System; provides appropriate services to ensure that the NBS staff has optimum accessibility to the scientific information of the world, and directs the public information activities of the Bureau. The Office consists of the following organizational units:

Office of Standard Reference Data-Office of Technical Information and Publications-Library-Office of Public Information-Office of International Relations.

\footnotetext{
1 Headquarters and Laboratories at Gaithersburg, Maryland, unless otherwise noted; mailing address Washington, D.C. 20234

2 Part of the Center for Radiation Research.

3 Located at Boulder, Colorado 80302.
} 
UNITED STATES DEPARTMENT OF COMMERCE - Maurice H. Stans, Secretary NATIONAL BUREAU OF STANUARIS - Lewis M. Branscomb, Director

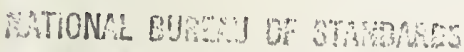

$14 \mathrm{H}$

\section{The Effect of Time Ordering On the Lyman $\alpha$ Profile}

J. T. Godfrey, C. R. Vidal, E. W. Smith, and J. Cooper

Quantum Electronics Division

Institute for Basic Standards

National Bureau of Standards

Boulder, Colorado 80302

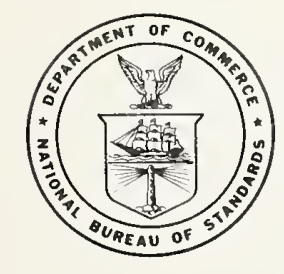

$t$

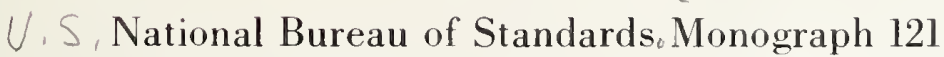

Nat. Bur. Stand. (U.S.), Monogr. 121, 14 pages (June 1971)

CODEN: NBSMA

Issued June 1971

For sale by the Superintendent of Documents, U.S Government Printing Oftce, Washington, D.C. 20402 (Order by SD Catalog No. C 13.44:121), Price 30 cents 
Table of Contents

1. Introduction _............

2. The Unified Theory Line Shape For Lyman-Alpha $\ldots \ldots \ldots \ldots$

3. Calculation of The Time-Ordered $\mathrm{U}_{1} \ldots \ldots \ldots \ldots$

4. The Fourier Transform $\mathrm{Of} \mathrm{C}(\mathrm{t})$ And The Profile $\ldots \ldots \ldots \ldots \ldots$

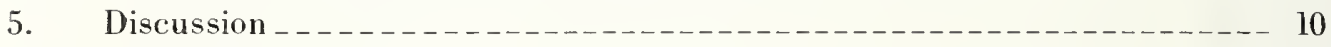

6. References _...

7. Appendix A _........ 12 


\title{
The Effect of Time Ordering on the Lyman $\alpha$ Profile
}

\author{
J. T. Godfrey*, C. R. Vidal, E. W. Smith \\ and J. Cooper**
}

\author{
National Bureau of Standards, Boulder, Colorado 80302
}

\begin{abstract}
Using a unified theory of spectral line broadening previously developed, the effects of time ordering over the complete line profile are investigated. The behavior of the time-ordered thermal average and un-time-ordered thermal average are compared. The Fourier transform of the thermal average is obtained analytically. Calculations for the line profite of the Lyman- $\alpha$ line of hydrogron are presented and are representative in that the full thermal average is replaced by the thermal average with the electron velocity distribution approximated by $f(v)=\delta\left(v-v_{a v}\right)$ where $v_{\text {av }}$ is the thormat velocity for the plasina in question.
\end{abstract}

hey words: Lyman- $\alpha$ : Stark-broadening: time-ordering: unified theory.

\section{Introduction}

Classical path calculations of Stark-broadened profiles have usually been made within the framework of two different models, valid over different regions of the profile. The impact theories of Griem, Kolb, and Shen [1] $]^{1}$ and Baranger [2] yield results appropriate to the line center $\Delta \omega \omega_{1}, \omega_{1}$, being the plasma frequency). In these theories, the electron collisions are assumed to be (ompleted and electron correlations are approximated by impact parameter cutoffs. Initially, the calculations of the S-operator were made to second order only. Later Shen and Cooper [3] were able to calculate the un-time ordered $S$-operator to all orders. In the other limit, quasi-static theories were used to describe the wings of the profite $\left(\Delta \omega \geq \Delta \omega_{c}, \Delta \omega_{c}\right.$ being the Weisskopf frequency). Recently, a "unified theory" has been developed by Smith, Cooper, and Vidal [4]. The expression for the line shape derived in this theory is (under certain conditions) vatid over the entire profile and yields both the impact and single perturber quasi-static results in the center and wings respectively.

Line profile calculations on the basis of the "unified theory" have been made for hydrogen by the same authors [5]. In describing the transition region from the line center to the line wings, the calculations include the effects of incompleted collisions through the use of a more general time-development operator which does not employ the usual completed collision assumption. Further, as in the case of Shen and Cooper [3], the calculations were made to all orders for the un-time-ordered exponential form of the time-development operator. The interaction potential was approximated to be of the dipole type and the ion broadening was treated as quasi-static. The correlation between the plasma perturbers was considered by cutting off the interaction potential at the Debye-length of the plasma. Additionally, for numerical convenience, a strong collision sphere was employed, inside which the collisions were assumed strong enough to destroy the phase coherence of the radiator. The radius of this sphere was taken to be $\rho_{0}=\pi+n^{2} a_{0}$ where $t$ is the thermal de Broglie wavelength of the colliding electron. Time-ordering was not included in these calculations.

In the $S$-matrix limit, Bacon, Shen, and Cooper [6] have investigated the effect of timeordering on the Lyman-alpha profile. In addition, their interaction potential included all terms in the multipole expansion. The results of these calculations indicate that a dipole type potential yields little deviation from the more general case including all multipole terms, until impact parameters smaller than about $3 \dot{t}$ are reached. The effects of level-splitting caused by the ionfields were ignored when calculating the time-development operator ( $S$-operator). The upper impact parameter cutoff was fixed at the Debye length and the lower impact limit was taken to be the thermal de Broglie wavelength of the perturbing electron.

The purpose of this paper is to present a model calculation of the effect of time-ordering on the resultant line shape as obtained within the framework of the "unified theory" of Smith. Cooper, and Vidal [4]. The calculation is representative in that the full thermal average is replaced by the thermal average evaluated at an average electron velocity for the plasma. The effects of incompleted collisions and a Debye-shielded potential, as well as a strong collision sphere cutoff on the potential were included. The results of the time-ordered calculation are compared with the un-time ordered result for Lyman-alpha. The calculations are done for an electron density of $10^{17} \mathrm{~cm}^{-3}$ and electron temperature of $20,000 \mathrm{~K} \mathrm{[6].}$

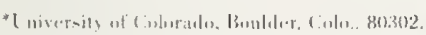

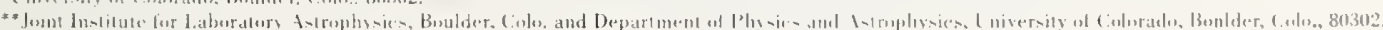

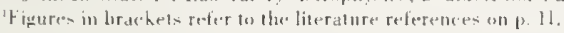




\section{The Unified Theory Line Shape for Lyman-Alpha}

The approximations inherent in a classical path treatment are well known $[7,8]$. In addition to these we will approximate the effects of the ion microfields in a quasi-static manner by regarding their collective field as essentially constant during the times of interest, $1 / \Delta \omega$. The final profile is obtained by averaging the line shape for a given static ion field over the distribution of ion fields for the plasma in question:

$$
y(\omega)=\int_{0}^{\infty} P(E) I(\omega, E) d E .
$$

The distribution function, $P(E)$, is the low frequency component of the fluctuating microfields in the plasma $[9,10]$. The line shape for a given static ion field obtained from the "unified theory" is given as [5]

$$
\left.I(\omega, E)=\frac{1}{\pi} \operatorname{Im} \sum_{\substack{\alpha \alpha^{\prime} \\ \beta \beta^{\prime}}}<\alpha|\mathbf{d}| \beta><\beta^{\prime}|\mathbf{d}| \alpha^{\prime}\right\rangle\langle\alpha|\rho| \alpha\rangle\left\langle\beta^{\prime} \alpha^{\prime}\left|\left[\Delta \omega_{\mathrm{op}}-\mathfrak{L}^{\prime}\left(\Delta \omega_{\mathrm{op}}\right)\right]^{-1}\right| \beta \alpha\right\rangle,
$$

where the sums are over atomic states. Matrix elements of $\Delta \omega_{0 \mathrm{p}}$ give the frequency perturbation from the position of the Stark component, shifted due to the static ion fields. The ${ }^{\circ}$-operator is defined within the impact approximation (not to be confused with the impact theory which makes the completed collision assumption) by the following expression:

$$
\mathcal{L}\left(\Delta \omega_{\mathrm{op}}\right)=-i \Delta \omega_{0 \mathrm{p}} \int_{0}^{\infty} e^{i t \Delta \omega_{\mathrm{op}}}<\tilde{U}_{1}-1>d t \Delta \omega_{\mathrm{op}}
$$

In general, the time-development operator is tetradic. This is necessary to include the effects of both upper and lower state perturbations; however, for the Lyman lines lower state interactions are negligible and the time-development operator between lower states may be replaced by a unit operator, thus, the time-development operator becomes

$$
\tilde{U}_{1}=\mathcal{O} \exp \left[-\frac{i}{\hbar} \int_{0}^{\mathrm{t}} \tilde{V}\left(t^{\prime}\right) d t^{\prime}\right] .
$$

Here $\mathcal{O}$ denotes the chronological ordering operator and the time-development operator has to be evaluated only between the upper states of the line.

The potential operator, $\widetilde{V}$ in the above expression is written in an interaction representation and is defined in terms of the classical interaction potential, $V$, by

$$
\tilde{V}(t)=e^{i t H_{0} / \hbar} V(t) e^{-i t H_{0} / \hbar}
$$

where $H_{0}$ is the Hamiltonian of the atomic system in the static ion field. In the expression for the $\mathcal{L}$-operator (eq. 2.3), the brackets around the time-development operator denote the usual thermal average over perturber states. In the classical path approximations the thermal average becomes

$$
\tilde{F}_{1}(t)=<\tilde{U}_{1}-1>=n_{e} \int d \mathbf{x}_{1} d \mathbf{v}_{1} W\left(v_{1}\right)\left[\tilde{U}_{1}\left(\mathbf{R}_{1}, \mathbf{x}_{1}, \mathbf{v}_{1}, t\right)-1\right],
$$

where $\mathbf{R}$ denotes the position of the atomic orbital electron, the perturbing electron position and velocity being $\mathbf{x}_{1}$ and $\mathbf{v}_{1}$ and the subscript one indicates a binary collision of a single electron (a consequence of the impact approximation). $W\left(v_{1}\right)$ is the classical electron velocity distribution appropriate to electrons of temperature $T_{e}$. Generally, this velocity distribution of the electrons is taken to be Maxwellian resulting in the distribution $W$ being related to the Maxwell distribution of speeds through $W\left(v_{1}\right)=f\left(v_{1}\right) / 4 \pi v_{1}{ }^{2}$. As mentioned earlier, however, in this calculation $f\left(v_{1}\right)$ is replaced by $\delta\left(v-v_{\mathrm{av}}\right)$ where $v_{\mathrm{av}}$ is the thermal velocity $v_{\mathrm{av}}=\sqrt{3 k T_{\mathrm{e}} / m}$, for the plasma in question. In terms of the more convenient collision variables (see Appendix of [8]), the thermal average reduces to

$$
\tilde{F}_{1}\left(v_{\mathrm{av}}, t\right)=\frac{n_{e} v_{\mathrm{av}}}{4 \pi} \int d \Omega \int_{0}^{\left.\rho_{l}\right)} \rho d \rho \int_{-x}^{x} d t_{0}\left[\tilde{U}_{1}\left(\mathbf{R}, \boldsymbol{\varrho}, \mathbf{v}_{\mathrm{av}}, t, t_{0}\right)-1\right] .
$$


Here $o$ points along the $z$-axis, $v_{\text {av }}$ along the $x$-axis and $t_{0}$ denotes some reference time of the perturber.

To obtain the line shape it is necessary to invert the matrix

$$
\left.\left.<\alpha \beta\left|\left[\Delta \omega_{0 \mathrm{p}}-\mathcal{L}^{\prime}\left(\Delta \omega_{\mathrm{op}}\right)\right]\right| \alpha^{\prime} \beta^{\prime}\right\rangle=\left[\omega-\left(E_{\beta}-E_{u}\right) \mid \hbar\right] \delta_{m, \prime^{\prime}} \delta_{\beta \beta^{\prime}}-<\alpha \beta\left|\alpha^{\prime}\left(\Delta \omega_{0 \mathrm{p}}\right)\right| \alpha^{\prime} \beta^{\prime}\right\rangle .
$$

with $|\alpha\rangle,\left|\alpha^{\prime}\right\rangle,|\beta\rangle$ and $\left|\beta^{\prime}\right\rangle$ being $H_{0}$ eigenstates. For hydrogen, the indicated eigenstates are taken to be parabolic. When considering well isolated lines such as Lyman-alpha, the off-diagonal elements in principal quantum number are generally small and the no-quenching approximation can be applied. Thus, matrix elements are taken to be non-zero only when occurring between states with the same principal quantum number. The $\mathfrak{L}$-operator matrix elements for Lymanalpha become

$$
<2 q m\left|\mathfrak{L}\left(\Delta \omega_{\mathrm{op}}\right)\right| 2 q^{\prime} m^{\prime}>=-i \Delta \omega_{2 q m} \Delta \omega_{2 q^{\prime} m^{\prime}} \int_{0}^{\infty} e^{i t \Delta \omega_{2 q m}}<2 q m\left|\tilde{F}_{1}\left(v_{\mathrm{av}}, t\right)\right| 2 q^{\prime} m^{\prime}>d t .
$$

where the dependence on $|\alpha\rangle$ and $\left|\alpha^{\prime}\right\rangle$ has been dropped since these states correspond to the single final state, $|100\rangle$, for Lyman-alpha which is essentially unperturbed as previously discussed. The quantum number $q$ is defined in terms of the usual parabolic quantum numbers, $n_{1}$ and $n_{2}$, according to $q=n_{1}-n_{2}$ and $m$ is the magnetic quantum number.

In order to obtain matrix elements of $F_{1}\left(v_{\text {av }}, t\right)$, we require elements of $\tilde{U}_{1}$ which in turn require matrix elements of the form

$$
<2 q m|\tilde{V}(t)| 2 q^{\prime} m^{\prime}>=\exp \left[\frac{i e}{\hbar}\left(Z_{2 q}-Z_{2 q^{\prime}}\right) E t\right]<2 q m|V(t)| 2 q^{\prime} m^{\prime}>.
$$

At this point we simplify the right hand side by invoking the sudden approximation which allows us to set the exponential equal to one in the preceding equation. This approximation has been dealt with in some detail by Van Regemorter [11] and will not be discussed further, however, it is made in previous Stark-broadening calculations (for a more complete discussion see reference [8]). Thus, matrix elements of $\tilde{V}(t)$ become simply matrix elements of the classical interaction potential. $V(t)$. In evaluating the thermal average of $F_{1}$ we have to perform the spherical average which is most conveniently done in spherical eigenstates. We rewrite the $\mathcal{L}$-operator matrix elements as

$<2 q m\left|\mathfrak{L}\left(\Delta \omega_{\mathrm{up}}\right)\right| 2 q^{\prime} m^{\prime}>=-i \Delta \omega_{2 q m} \Delta \omega_{2 q^{\prime} m^{\prime}} \sum_{\|^{\prime}}<2 q m\left|2 l m><2 l^{\prime} m^{\prime}\right| 2 q^{\prime} m^{\prime}>$

$$
\times \int_{0}^{\infty} \mathrm{e}^{i t \Delta \omega_{2 q m}}<2 l m\left|F_{1}\left(v_{a r}, t\right)\right| 2 l^{\prime} m^{\prime}>d t .
$$

The transformation coefficients between spherical and parabolic states, $\left\langle n q m \mid n^{\prime} l^{\prime} m^{\prime}\right\rangle$. have been obtained by Hughes [12] and are diagonal in magnetic quanłum number.

Returning to the calculation of the thermal average, we must evaluate the following expression:

$$
<2 l m\left|F_{1}\left(v_{\mathrm{a},}, t\right)\right| 2 l^{\prime} m^{\prime}>=\frac{n_{e} v_{\mathrm{av}}}{4 \pi} \int_{0}^{\rho_{D}} \rho d \rho \int_{-\infty}^{\infty} d t_{0} \int d \Omega\left[<2 l m\left|U_{1}\right| 2 l^{\prime} m^{\prime}>-1\right] .
$$

$U_{1}$ is evaluated in the collision axes. In performing the angular average, the atomic axes are rotated through $\Omega$ into the space axes defined by $g$ and $\mathbf{v}$. The angular average then becomes

$$
\begin{aligned}
\int d \Omega\left[<2 l m\left|U_{1}\right| 2 l^{\prime} m^{\prime}>-1\right] & =\sum_{\mu \mu} \int d \Omega\left[D_{m \mu}^{\prime \prime}(\Omega)<2 l \mu\left|U_{1}\right| 2 l^{\prime} \mu^{\prime}>D_{\mu \prime \prime \prime}^{\prime \prime}(\Omega)-1\right] \\
& =\frac{8 \pi^{2}}{2 l+1} \sum^{\prime}\left[<2 l m\left|U_{1}\right| 2 l m>-1\right] \delta_{l \prime \prime} \delta_{m m m^{\prime}} .
\end{aligned}
$$


where the $D$ matrices are the conventional rotation matrices [13].

The thermal average now becomes

$$
<2 l m\left|F_{1}\left(v_{\mathrm{av}}, t\right)\right| 2 l^{\prime} m^{\prime}>=2 \pi n_{e} v_{\mathrm{av}} \int_{0}^{\rho_{D}} \rho d \rho \int_{-\infty}^{\infty} d t_{0}\left\{\frac{1}{2 l+1} \sum_{m=-l}^{l}\left[<2 l m\left|U_{1}\right| 2 l m>-1\right]\right\} \delta_{l l^{\prime}} \delta_{m m^{\prime}}
$$

which is diagonal in spherical states. Thus, only the elements $\left.<200\left|F_{1}\right| 200\right\rangle$ and $\left.<21 m\left|F_{1}\right| 21 m\right\rangle$ are needed for the line shape. (These elements are independent of $m$ as a result of the spherical average.)

\section{Calculation of the Time-Ordered $\mathrm{U}_{1}$}

To obtain the full time-ordered time development operator, one may integrate the differential equation defining this operator (the subscript one will be dropped for the remaining discussion and a binary collision is assumed to be considered). In order to obtain the differential equation in terms of the collision variable, $t_{0}$, we differentiate the Dyson expansion of the time-development operator (see, for example, reference [14] page 240) with respect to $t_{0}$ where this expansion is given by

$$
U\left(t+t_{0}, t_{0}\right)=1+\sum\left(\frac{-i}{\hbar}\right)^{n} \int_{t_{n}}^{t+t_{0}} d t_{1} \int_{t_{n}}^{t_{2}} d t_{2} \ldots \int_{t_{0}}^{t_{n-1}} d t_{n} V\left(t_{1}\right) V\left(t_{2}\right) \ldots V\left(t_{n}\right) .
$$

The resulting differential equation becomes

$$
i \hbar \partial / \partial t_{0}, U\left(t+t_{0}, t_{0}\right)=V\left(t+t_{0}\right) U\left(t+t_{0}, t_{0}\right)-U\left(t+t_{0}, t_{0}\right) V\left(t_{0}\right) .
$$

Up to this point no mention of the form of the interaction potential has becn made. In principal, the full multipole expansion of the potential can be used; however, this would result in prohibitively long machine calculations. Further, since a dipole approximation of the interaction yields the major contribution to time-ordering [6] this form of the potential was used. Using the Debye-cutoff and the strong-collision cutoff, the interaction potential is given as

$$
V(t)= \begin{cases}\mathrm{O} & \left(r_{p}>\rho_{0}\right) \\ \frac{e^{2} R}{r_{\mathrm{p}}^{2}(t)} \sum_{q=-1}^{+1}(-1)^{q} C_{-q}^{(1)}(\hat{R}) C_{q}^{(1)}\left(\hat{r}_{p}\right) & \left(\rho_{\min }<r_{p}<\rho_{0}\right) \\ \mathrm{O} & \left(r_{p}<\rho_{\min }\right)\end{cases}
$$

where $C_{q}^{(k)}=\sqrt{4 \pi /(2 k+1)} Y_{k q}, R$ is the position of the orbital electron and $r_{p}=\sqrt{\rho^{2}+v_{\mathrm{av}}^{2}} t^{2}$ is the radial position of the perturber. In effect, the perturber is considered to remain outside the atomic dimensions as required by the classical path theory. The hard sphere cut-off, $\rho_{\min }$, was taken at the thermal wavelength of the colliding electron. In terms of spherical eigenstates, eq. (3.2) becomes for Lyman-alpha

$i \hbar \partial / \partial t_{0}<2 l m|U| 2 l^{\prime} m^{\prime}>=\sum_{l, M}\left[<2 l m\left|V\left(t+t_{0}\right)\right| 2 L M><2 L M|U| 2 l^{\prime} m^{\prime}>\right.$

$$
\left.-<2 l m|U| 2 L M><2 L M\left|V\left(\mathrm{t}_{0}\right)\right| 2 l^{\prime} m^{\prime}>\right] .
$$

The cutoff on the potential at the Debye-sphere and the strong-collision sphere make the calculations velocity dependent for all values of the collision variables. For values of $\rho>>10 \star$ we find that the real parts of the matrix elements in eq. (3.4) become equal to the un-time ordered values. As discussed in more detail at the end of this section, this is merely a consequence of the fact that a second order expansion of the time-development operator is valid in this region. In this region $U$ was approximated by $U_{0}$ where

$$
U_{0}=\exp \left[-\frac{i}{\hbar} \int_{t_{10}}^{t+\ell_{n}} V\left(t^{\prime}\right) d t^{\prime}\right]
$$


The calculation of the un-time ordered thermal average for the "unified theory" line shape has been discussed in detail in the reference mentioned earlier [5]. At very small impact parameters

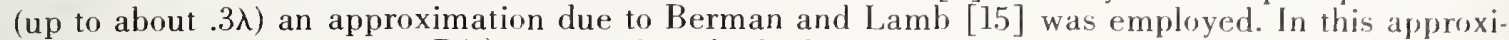
mation a unitary operator $R(t)$ is introduced which instantaneously diagonalizes the interaction potential. The time-ordered time-development operator is then approximately given by

$$
U\left(t+t_{0}, t_{0}\right)=R^{\dagger}\left(t+t_{0}\right)\left[\exp \left\{-\frac{i}{\hbar} \int_{t_{0}}^{t+t_{10}} V_{D}\left(t^{\prime}\right) d t^{\prime}\right\}\right] R\left(t+t_{0}\right),
$$

where $V_{D}(t)=\frac{e^{2} R}{r_{p}^{2}(t)} C_{0}{ }^{(1)}(\hat{R}) C_{0}{ }^{(1)}\left(\hat{r}_{p}\right)$.

The region of validity of this approximation occurs for values of $\rho<<\rho_{k}$ ( $\rho_{u}$ being the Weisskopf collision radius defined as $\left.\sqrt{2 / 3} \star n^{2}\right)$. In the intermediate region $(.3 \star<\rho \leq 10 \star)$ eqs. (3.4) were integrated numerically (Appendix A). For large interaction times, the time development operator has to converge to the $S$-matrix limit according to [8]

$$
\left.\lim _{t \rightarrow \infty} \int_{-\infty}^{\infty} d t_{0}[\mathrm{U}-1]\right]_{\mathrm{av}}=\lim _{t \rightarrow \infty} t[\mathrm{~S}-1]_{\mathrm{av}} .
$$

This convergence allowed the time-development operator to be replaced by the $S$-operator for values of $t$ which were found to satisfy $\mathrm{t}>>10 / \omega_{p}$ ( $\omega_{p}$ being the plasma frequency). Physically this corresponds to times of interest large enough such that virtually all collisions are completed. The solution of the time-ordered $S$-operator required a Debye cut-off and hard sphere cut-off on the interaction potential and in this respect differed slightly from the previously mentioned calculation of Bacon, Shen and Cooper [6]. (Also, the full thermal average was replaced by the thermal average evaluated at the thermal velocity.)

For comparison, the un-time ordered time-development operator of eq. (3.5) was calculated in spherical states. This calculation differed from that of Vidal, Cooper, and Smith [5] only in that the thermal average was evaluated at the thermal velocity instead of making the full velocity average. From the results for the $U$-operator and the un-time ordered $U_{0}$-operator, it was possible to generate a difference function, $D(t)=U(t)-U_{0}(t)$, which represents the effect of time-ordering.

This effect is illustrated by figure 1 , in which we plot the ratio $C(t) / F(t)$ as a function of time for the $(200)$ and $(2 \mathrm{~lm})$ matrix elements of the thermal average. Here $C(t)$ is the thermal average of $D(t)$ and $F(t)$ the thermal average of the time-ordered time-development operator $U(t)$. The time scale is normalized with respect to the inverse of the plasma frequency such that

$$
s=\tilde{\omega}_{p}, t=\sqrt{2} \omega_{p} t .
$$

The effect of time-ordering is negligible for small times of interest corresponding to the static limit where $\Delta \omega \geq \Delta \omega_{r}$. and increases monotonically to a constant value for large times of interest. The largest effect on the thermal average occurs for times greater than about $.1 / \tilde{\omega}_{p}$ and for the (200) element is a 14 percent decrease while for the $(21 \mathrm{~m})$ element it is a 11 percent increase. The accuracy of the calculations for $C(t) / F(t)$ correspond to $\sim \pm .005$.

In order to clarify again the effect of time ordering on the time development operator, one can rewrite eq. (3.1) in the following manner [16]:

$$
\begin{aligned}
& U\left(t+t_{0}, t_{t}\right)=\exp \left[-\frac{i}{\hbar} \int_{t^{\prime \prime}}^{t+t^{\prime \prime}} V\left(t^{\prime}\right) d t^{\prime}\right] \exp \left[\frac{1}{2}\left(\frac{-i}{\hbar}\right)^{2} \int_{t^{\prime \prime}}^{t+t_{0}} d t^{\prime} \int_{t^{\prime \prime}}^{t^{\prime}} d t^{\prime \prime}\left[V\left(t^{\prime}\right), V\left(t^{\prime \prime}\right)\right]\right. \\
& \times \exp ,\left[\frac { 1 } { 3 } ( \frac { - i } { \hbar } ) ^ { 3 } \int _ { t ^ { \prime \prime } } ^ { t ^ { + } t ^ { \prime \prime } } d t ^ { \prime } \int _ { t _ { 0 } } ^ { t _ { 1 1 } } d t ^ { \prime \prime } \int _ { t ^ { \prime \prime } } ^ { t ^ { \prime \prime } } d t ^ { \prime \prime \prime } \left\{\left[V\left(t^{\prime \prime \prime}\right),\left[V\left(t^{\prime \prime}\right), V\left(t^{\prime}\right)\right]\right]+\left[V\left(t^{\prime \prime}\right),\left[V\left(t^{\prime \prime \prime}\right), V\left(t^{\prime}\right)\right]\right] \times \ldots\right.\right.
\end{aligned}
$$




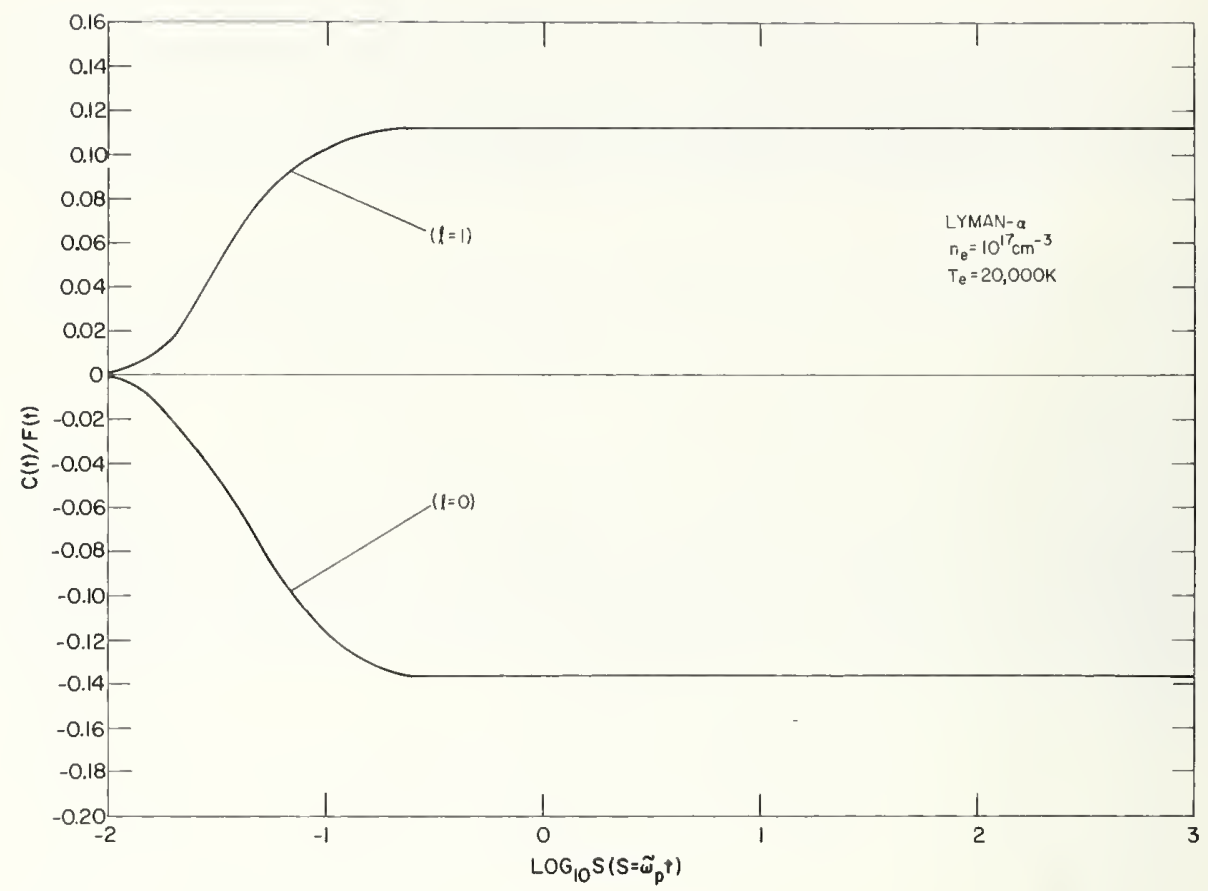

FIGURE 1. Ratio of the thermally averaged difference function to the thermal average of the timeordered time-development operator. The time scale is normalized with respect to the inverse of the plasma frequency $\left(\mathrm{s}=\tilde{\omega}_{\rho} \mathrm{t}=\sqrt{2} \omega_{\rho} \mathrm{t}\right)$.

Clearly, if the commutators in the above expression can be ignored, time-ordering is unimportant. For collisions which are weak $(V \tau / \hbar<1$ where $\tau$ is the collision time and $V$ the interaction potential) it is apparent that this condition holds. It is this fact which leads to the convergence of $U$ to the un-time-ordered result for impact parameters greater than about $10 \mathrm{t}$. In the quasi-static region, $\Delta \omega \tau>>1$, it can also be shown [8] that the commutators are negligible. Thus, we anticipate that in the static limit, for small times of interaction, the time-ordered and the un-time-ordered results for the time-development operator will coincide.

\section{The Fourier Transform of $\mathrm{C}(\mathrm{t})$ and the Profile}

The thermal average of the time-ordered time development operator is defined by

$$
F_{1}(t)=F_{1}^{0}(t)+C(t)
$$

where $\mathrm{F}_{1}^{0}(t)$ is the un-time ordered thermal average. Evaluation of the ${ }^{R}$-operator matrix elements in eq. (2.9) requires the Fourier Transform of $F_{1}$. As the Fourier Transform of $F_{1}^{0}(t)$ has been obtained elsewhere [5], we will concern ourselves with the transform of the difference function, $C(t)$. We require the transform of both elements

$$
<200|C(t)| 200>\quad \text { and } \quad<2 \operatorname{lm}|C(t)| 21 \mathrm{~m}>.
$$

Denoting these as $C^{(1)}(t)$ and $C^{(2)}(t)$, respectively, it is now possible to proceed in a manner similar to that used for obtaining $F_{1}^{\prime \prime}(\Delta \omega)$. In terms of the variable $s$ (eq. (3.8) ) and the frequency variable

$$
\Delta \tilde{\omega}_{q}=\left(\Delta \omega-\frac{3 e E a_{0}}{\hbar} q\right) / \tilde{\omega}_{p}
$$

where $\Delta \omega=\omega-\omega_{0}, \Delta \omega$ is the frequency perturbation from the position of the unperturbed line $\omega_{11}$, we require

$$
C^{\prime \prime}\left(\Delta \tilde{\omega}_{q}\right)=\frac{1}{\pi} \int_{0}^{\infty} e^{i \Delta \tilde{\omega}_{l,} s} C^{\prime \prime}(s) d s . \quad(n=1,2)
$$


As in the case of $F_{1}^{0}, C^{n}(s)$ diverges at large values of $s$ because of the negleet of the finite lifetimes of the states involved in the line. We thus introduce again a convergence factor exp $(-\epsilon s)$ and evaluate

$$
C^{n}\left(\Delta \tilde{\omega}_{q}\right)=\lim _{\epsilon \rightarrow 1} \frac{1}{\pi} \int_{0}^{x} e^{-\left(\epsilon-i \Delta \tilde{\omega}_{q}\right) s} C^{n}(s) d s .
$$

In performing the transform, it is convenient to fit $C^{\prime \prime}(s)$ with an analytic function. Unfortunately, the small $s$ behavior is not known analytically; however, both $F_{1}(s)$ and $F_{1}^{0}(s)$ are known to go as $s^{3 / 2}$ for small $s$. Consideration of the results of Berman and Lamb [15] indicate that for small times of interest $C^{\prime \prime}(s)$ is expected to go as a half-integer power of $s$. It was found that a function of the form

$$
\lim _{s \rightarrow 0} H^{n}(s)=h_{1}^{n} s^{7 / 2}+h_{2}^{n} s^{9 / 2}+\ldots
$$

fit the available data. A suitable function which has both the large $s$ asymptotic behavior and goes as eq. (4.5) for small $s$ was satisfied by a function of the general form

$$
\begin{aligned}
H^{n}(s) & =\sum_{k} H_{k}^{n}(s) \\
& =\sum_{k} \frac{a_{h}^{n} \cdot s^{3 k+3}}{\left(s^{2}+2 b_{h}^{n} \cdot\right)^{2 k+1 / 2}} .
\end{aligned}
$$

The transform $C^{\prime \prime}\left(\Delta \tilde{\omega}_{11}\right)$ is then given by

$$
\begin{aligned}
C^{n}\left(\Delta \tilde{\omega}_{q}\right) & =\sum_{k} \lim _{\epsilon \rightarrow 0} \frac{1}{\pi} \int_{0}^{\infty} e^{-\left(\epsilon-i \Delta \tilde{\omega}_{q}\right) s} H_{k}^{n}(s) d s \\
& =\sum_{k} \frac{a_{k}^{n}}{\sqrt{\pi}} \frac{(-1)^{k+1}}{2^{2 k} \Gamma\left(2 k+\frac{1}{2}\right)} \lim _{\epsilon \rightarrow 0}\left(\frac{d}{d \epsilon}\right)^{k+3}\left(\frac{d}{d b_{k}^{n}}\right)^{2 k}\left\{e^{b_{k}^{n}\left(\epsilon-i \Delta \tilde{\omega}_{l^{\prime}}\right)} \times K_{0}\left[b_{k \cdot}^{n}\left(\epsilon-i \Delta \tilde{\omega}_{q}\right)\right]\right\}
\end{aligned}
$$

where $K_{0}$ is the modified Bessel function of zero order. The number of terms included above is determined by the desired accuracy of the fit. In the calculation presented here it was possible to fit $C^{\prime \prime}(s)$ down to small values of $s$ with the first two terms of equation (4.6) ( $k=1$ and $k=2$ terms). Writing these terms out explicitly, we have the following:

$$
\begin{aligned}
& H_{1}^{\prime \prime}\left(\Delta \omega_{q}\right)=a_{1}^{n}\left(b_{1}^{\prime \prime}\right)^{2} e^{-i Z_{1}^{\prime \prime}}\left\{\left[16 Z_{1}^{n} J_{0}\left(Z_{1}^{n}\right)+\left(\frac{32}{6}\left(Z_{1}^{n}\right)^{2}-9\right) Y_{0}\left(Z_{1}^{n}\right)-\left(\frac{32}{6}\left(Z_{1}^{\prime \prime}\right)^{2}-3\right) J_{1}\left(Z_{1}^{n}\right)\right.\right. \\
& \left.+\left(\frac{80}{6} Z_{1}^{n}+\frac{1}{2 Z_{1}^{n}}\right) Y_{1}\left(Z_{1}^{n}\right)\right]+i\left[16 Z_{1}^{n} Y_{0}\left(Z_{1}^{n}\right)-\left(\frac{32}{6}\left(Z_{1}^{n}\right)^{2}-9\right) J_{0}\left(Z_{1}^{n}\right)\right. \\
& \left.\left.-\left(\frac{32}{6}\left(Z_{1}^{n}\right)^{2}-3\right)^{\prime \prime} Y_{1}\left(Z_{1}^{n}\right)-\left(\frac{80}{6} Z_{1}^{n}+\frac{1}{2 Z_{1}^{\prime \prime}}\right) J_{1}\left(Z_{1}^{n}\right)\right]\right\} \\
& H_{2}^{\prime \prime}\left(\Delta \tilde{\omega}_{q}\right)=-\frac{a_{2}^{n} b_{2}^{n}}{210} e^{-i Z_{2}^{\prime \prime}}\left\{\left[\left(4200 Z_{2}^{n}-2112\left(Z_{2}^{n}\right)^{n}\right) J_{0}\left(Z_{2}^{n}\right)-\left(256\left(Z_{2}^{n}\right)^{4}-5136\left(Z_{2}^{n}\right)^{2}+945\right) Y_{0}\left(Z_{2}^{n}\right)\right.\right. \\
& \left.+\left(256\left(Z_{2}^{n}\right)^{4}-4176\left(Z_{2}^{n}\right)^{2}+105\right) J_{1}\left(Z_{2}^{n}\right)-\left(1984\left(Z_{2}^{n}\right)^{3}-2328 Z_{2}^{n}\right) Y_{1}\left(Z_{2}^{\prime \prime}\right)\right] \\
& +i\left[\left(256\left(Z_{2}^{\prime \prime}\right)^{4}-5136\left(Z_{2}^{\prime \prime}\right)^{2}+945\right) J_{0}\left(Z_{2}^{\prime \prime}\right)+\left(4200 Z_{2}^{\prime \prime}-2112\left(Z_{2}^{\prime \prime}\right)^{3}\right) Y_{0}\left(Z_{2}^{\prime \prime}\right)\right. \\
& \left.\left.+\left(256\left(Z_{2}^{\prime \prime}\right)^{4}-4176\left(Z_{2}^{\prime \prime}\right)^{2}+105\right) Y_{1}\left(Z_{2}^{\prime \prime}\right)+\left(1984\left(Z_{2}^{\prime \prime}\right)^{3}-2328 Z_{2}^{\prime \prime}\right) J_{1}\left(Z_{1}^{\prime \prime}\right)\right]\right\}
\end{aligned}
$$


where $Z_{1}^{n}=b_{1}^{n} \Delta \tilde{\omega}_{q}$ and $Z_{2}^{n}=b_{2}^{n} \Delta \tilde{\omega}_{q}$. The functions $J_{0}, Y_{0}, J_{1}$, and $Y_{1}$ are Bessel functions of zero and first order. For large arguments of $Z_{1}^{n}$ or $Z_{2}^{n}$ the following asymptotic expansions are useful:

$$
\begin{aligned}
& \lim _{Z_{1}^{n} \rightarrow \infty} H_{1}^{n}\left(\Delta \tilde{\omega}_{q}\right)=\frac{315}{6 \cdot 8^{2}} \frac{a_{1}^{n} b_{1}^{n}}{\sqrt{\pi}} \frac{1}{Z_{1}^{n}}\left[(1+i)+\frac{45}{8} \frac{(1+i)}{Z_{1}^{n}}-\frac{15 \cdot 21 \cdot 44}{8^{3}} \frac{(1+i)}{Z_{1}^{n}{ }^{2}}+\ldots\right] \\
& \lim _{Z_{2}^{n} \rightarrow \infty} H_{2}^{n}\left(\Delta \tilde{\omega}_{q}\right)=-\frac{a_{2}^{n} b_{2}^{n}}{2 \cdot 3 \cdot 5 \cdot 7} \frac{1}{\sqrt{\pi}} \frac{1}{Z_{2}^{n ! 11 / 2}}\left[(193.8)(1-i)-\frac{(2398.3)(1+i)}{Z_{2}^{n}}-\frac{(21434.5)(1-i)}{Z_{2}^{n}{ }^{2}}+\ldots\right] .
\end{aligned}
$$

In addition, for small values of $\Delta \tilde{\omega}_{q}, C^{n}\left(\Delta \tilde{\omega}_{q}\right)$ is approximated by

$$
\lim _{\Delta \tilde{\omega}_{q} \rightarrow 0} C^{\prime \prime}\left(\Delta \tilde{\omega}_{q}\right)=-\frac{a_{1}^{n}}{\pi} \frac{1}{\Delta \tilde{\omega}_{q}^{2}}-i \frac{6 a_{1}^{n} b_{1}^{n}}{\pi \Delta \tilde{\omega}_{q}}+\ldots
$$

In order to compare the results of the transform of $C^{n}(t)$ with the thermal average of the time-ordered time-development operator, it was necessary to obtain $F_{1}^{0}\left(\Delta \tilde{\omega}_{q}\right)$. In order to get this function, we approximate $F_{1}^{0}(s)$ with a function $G(s)=G_{1}(s)+G_{2}(s)$ for both the $(200)$ and $(2 \mathrm{~lm})$ elements. The functions $G_{1}(s)$ and $G_{2}(s)$ are the same as those defined by Vidal, Cooper, and Smith [5] and are given in terms of the normalized time variable as

$G^{n}(s)=G_{1}^{n}(s)+G_{2}^{\prime \prime}(s)=\frac{a_{1}^{n} s^{2}}{\left(s^{2}+2 b_{1}^{u} s\right)^{1 / 2}}+\frac{a_{2}^{\prime \prime} s^{5}}{\left(s^{2}+2 b_{2}^{u} s\right)^{5 / 2}}$.

The transform of the time-ordered thermal average now satisfies

$$
\bar{F}_{1}^{n}\left(\Delta \tilde{\omega}_{q}\right)=G^{n}\left(\Delta \tilde{\omega}_{q}\right)+C^{n}\left(\Delta \tilde{\omega}_{q}\right),
$$

where $G^{n}\left(\Delta \tilde{\omega}_{q}\right)$ denotes the transform of $G^{n}(s)$ defined in eq. (4.11).

In figure 2 we have plotted the real part of $C^{n}\left(\Delta \tilde{\omega}_{q}\right) / F_{1}^{u}\left(\Delta \tilde{\omega}_{q}\right)$ versus the logarithm of $\Delta \tilde{\omega}_{q}$ for the $(200)$ and $(21 \mathrm{~m})$ elements. Realizing that for a frequency perturbation $\Delta \omega$ we are mainly interested in times of the order or smaller than $1 / \Delta \omega$, such that

$$
\Delta \omega \Delta t \gtrsim 1
$$

we see that in agreement with figure 1 , the largest contribution to the transformed thermal average occurs for small $\Delta \omega$. Unlike the effects of electron correlations on the transform, which are important for values of $\Delta \omega \lesssim \omega_{p}$, the effects of time-ordering extend somewhat further into the wings. As expected, however, in the distant line wings where quasistatic collisions occur, $\left(\Delta \omega \gtrsim \Delta \omega_{c}\right)$ the effects of time-ordering are negligible. The accuracy of the calculation of $C^{n}\left(\Delta \tilde{\omega}_{q}\right) F_{1}^{n}\left(\Delta \tilde{\omega}_{q}\right)$ is $\sim \pm .01$. The Weisskopf frequency, defined for Ly- $\alpha$ as $\Delta \omega_{c}=v_{r}^{2} / \frac{3 \hbar}{m}$ with $v_{c}=\sqrt{\frac{2 k T}{m}}$, is also marked.

The Lyman-alpha profile is obtained by evaluation of eq. (2.2) followed by averaging over the distribution of ion fields appropriate to the plasma in question. This distribution, $P(E)$, is taken to be the one given by Hooper as previously mentioned $[9,10]$. In order to see the effect of timeordering on the full profile, the calculation of the un-time-ordered profile was obtained with the thermal average approximated by the $G$ function of eq. (4.11). The time-ordered result was obtained by calculating the profile with the thermal average of eq. (4.12). In figure 3 we have plotted the ratio $\Delta y / y_{F}$, versus $\Delta \omega$ where

$$
\Delta y^{\prime} \mathfrak{y}_{1}, \mathfrak{y}_{i} \cdot
$$

$\Delta_{3} y$ is the difference between the two line profiles based on the ordered and un-ordered timedevelopment operators. $y_{F_{1}}$ is the time-ordered profile. 


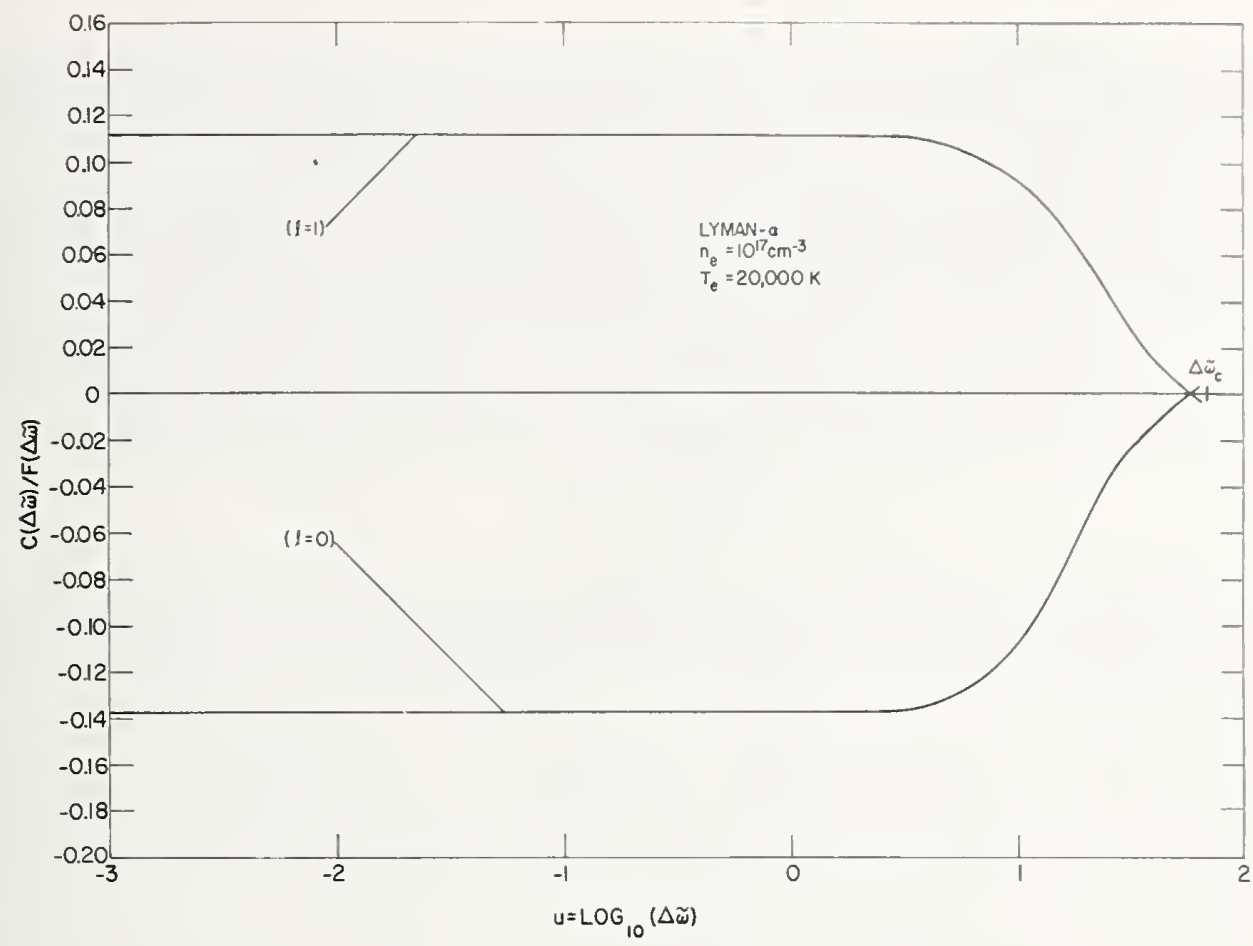

FlGLRE 2. The ratio $\mathrm{C}^{\mathrm{n}} / \mathrm{F}_{\mathrm{l}}^{\mathrm{n}}$ versus $\lrcorner \tilde{\omega}_{\mathrm{q}} \cdot \mathrm{C}^{\mathrm{n}}\left(\Delta \tilde{\omega}_{\mathrm{q}}\right)$ is the Fourier transform of the thermally averaged difference function between the ordered and the un-ordered timetdevelopment operators. $\mathrm{F}_{1}^{n}\left(\lambda \tilde{\omega}_{4}\right)$ is the Fourier transform of the time-ordered thermal average.

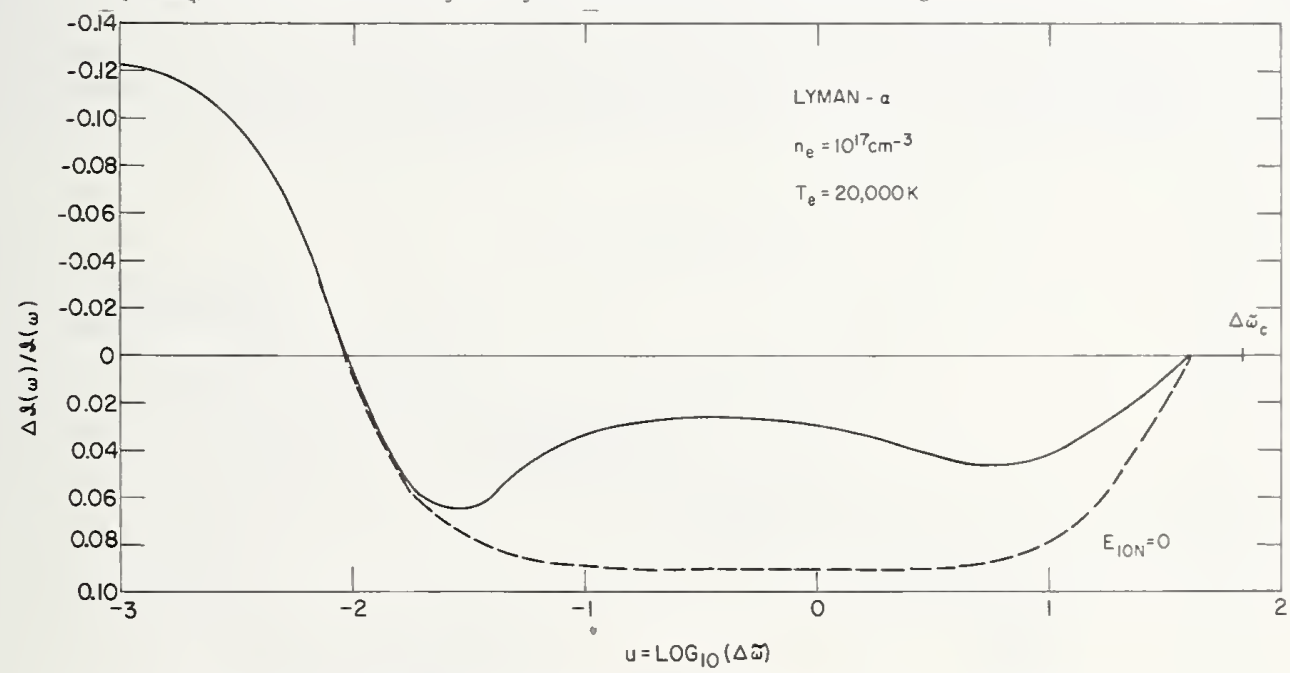

FIGLRE 3. The ratio $J$ il versus $\Delta \omega$ uhere $\rfloor$ is the difference between the two line profiles based on the ordered and un-ordered time-development operators. It is the time-ordered profile.

The "unified theory" yields a normalized profile; consequently, as expected the contribution $\Delta J$ is normalized to zero. In the same plot we show the results with the ion microfield average removed.

It is clear from figure 3 that the effect of time-ordering in the line center is to decrease the intensity. The profile increases in intensity as we go towards the wings until we reach roughly one-tenth the plasma frequency. It then decreases followed by a smaller increase near ten times the plasma frequency. This latter increase is attributable to the effects of time-ordering near the shifted Stark component. To demonstrate this we have included in figure 3 the case where the Stark splitting due to the ions has been neglected by setting $E_{\text {ion }}=0$. To summarize. it appears that the effect of time-ordering on the final line profile tends to smear out the structure near the line center. 
In the results of Bacon, Shen, and Cooper [6] the final profiles were normalized to one in the line center. A plot of the data from this calculation yields an increase in the half-width of the line due to time ordering by about 14 percent (this is in close agreement with the results of the Bacon, Shen, and Cooper calculation versus that for the Shen-Cooper case [3]).

As one goes towards larger values of $u$ (where $u=\log _{10}(\Delta \tilde{\omega})$ in figs. 2 and 3 ), we realize that the influence of time-ordering decreases. Since the time-development operator has been calculated with the same accuracy over the entire range, the numerical accuracy of $C^{n}\left(\Delta \tilde{\omega}_{a}\right) / F_{1}^{n}\left(\Delta \tilde{\omega}_{a}\right)$ decreases as one goes to large $u$; however, for values of $u$ larger than one, the profile is already down by a factor of $10^{6}$ from its value at the line center. Thus, we have discontinued the plots at $u=1.6$ (where the profile is about $10^{8}$ below the value at line center). The effects below this point reflect primarily the error introduced in fitting the $C^{n}(s)$ at very small times of interest (see eq. (4.5) ) causing the ratio $\Delta J / \zeta^{2}$, to go slightly negative before returning to zero.

\section{Discussion}

The calculation presented here was made within the framework of the classical path model, the effects of incompleted collisions and the full time-ordering. It was representative in that the full thermal average was replaced by the thermal average evaluated at the thermal velocity $\left(v_{\text {av }}=\sqrt{3 k T, / m)}\right.$. The case considered corresponds to an electron density of $10^{17}$ electrons per cubic centimeter and an electron temperature of $20,000 \mathrm{~K}$ with the interaction potential taken to be of the dipole type. The calculations were made with the "unified thcory" line shape of Smith, Cooper, and Vidal [4] and for comparison the un-time-ordered time-development operator was also calculated at $v_{\text {av }}$.

The effect of time-ordering on the thermal average was found to increase monotonically with time. For the Lyman-alpha line (the case considered) the correction to the (200) matrix element approaches a constant value of about -14 percent for large values of time while for the $(21 \mathrm{~m})$ matrix element the correction approaches +11 percent. The direction in which the correction occurs for these elements (decreases the $(200)$ and increases the $(21 \mathrm{~m})$ with respect to the untime-ordered case) is in agreement with the impact calculation of Bacon, Shen, and Cooper [6]. The influence of time-ordering is still important at times of interest somewhat smaller than $t=1 / \omega_{\mu}$; however, it eventually drops off to zero at values of $t \sim 1 / \Delta \omega_{c} \cdot\left(\Delta \omega_{c}=2 k T_{e} / 3 \hbar\right.$. This behavior is reflected in the Fourier transform where we find an inverse behavior in frequency space.

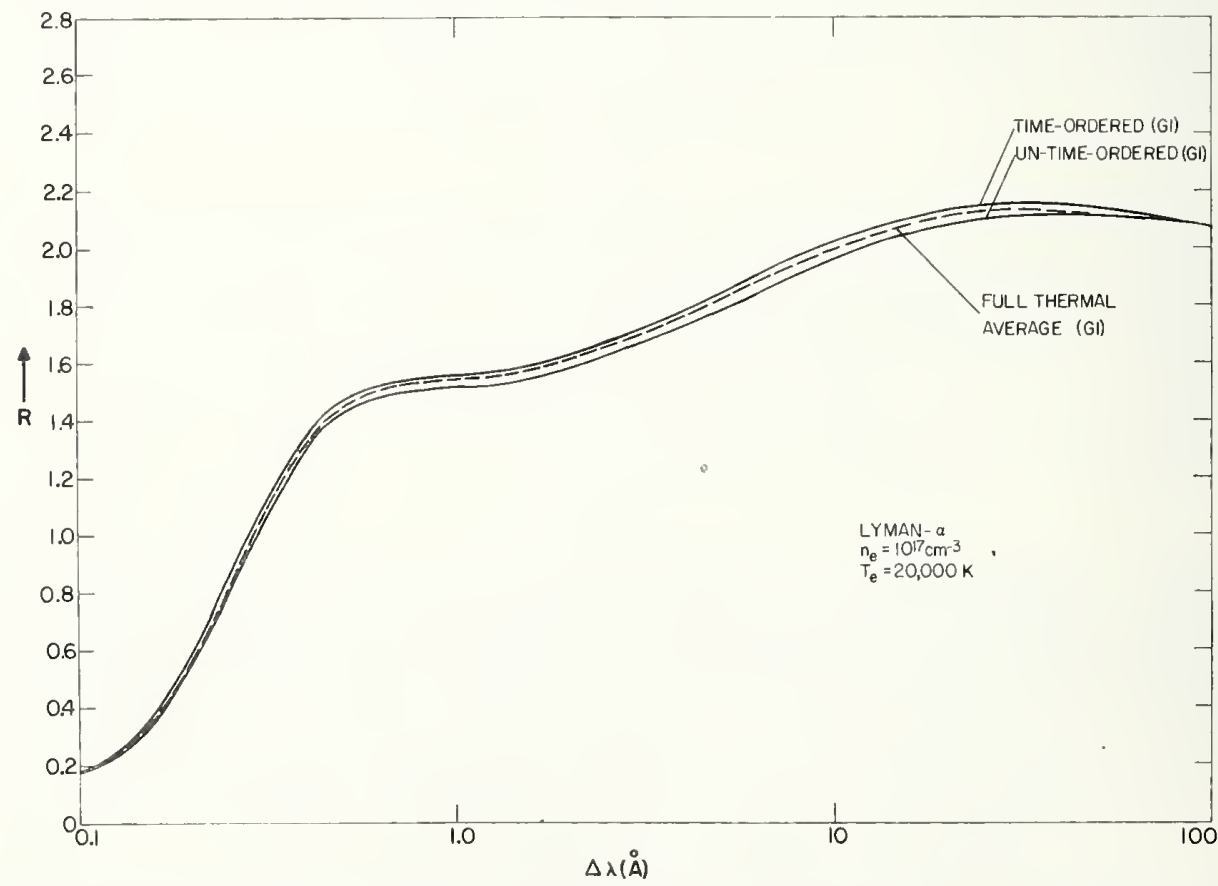

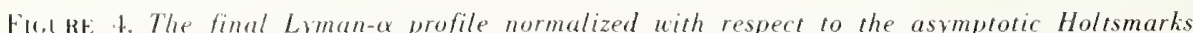
$\Delta \lambda^{-5,2}$-ring (ions only) for the time-ordered and un-time-ordered (including the case where a full thermal alerage is made) time-detelopment operators $\left(\Delta \lambda_{c}=137 \mathrm{~A}\right)$. 
The largest correction takes place for small values of $\Delta \omega$ with the effects extending past the plasma frequency and finally dropping off to zero in the wings $\left(\Delta \omega>\Delta \omega_{r}\right)$.

The influence on the profile was the greatest in the line center where the intensity was found to decrease by about 12 percent. The half-width increases over the un-time-ordered result by about 14 percent. This is in agreement with a comparison of the impact calculation [6] and the results of Shen and Cooper [3]. As one goes towards the wings of the profile the effect of timeordering eventually causes an increase in the intensity of the profile. This increase is smoothed out over a fairly large region with a distinct peak occurring at slightly less than an order of magnitude past the plasma frequency. This increase results from the effects of time-ordering in the vicinity of the Stark component shifted due to the ion fields. Beyond about ten times the plasma frequency time-ordering ceases to be important. In figure 4 we have plotted the ratio of the profile to the Holtsmark $\Delta \omega^{-5 / 2}$ wing (resulting from considering only the ions). The un-timc ordered result is also plotted along with the un-time-ordered result obtained using a fult thermat average (dotted line).

In this plot only the $G_{1}$ term of eq. (4.11) has been considered. As mentioned above, the effect of time ordering is to lower the Ly- $\alpha$ profile in the center and to increase it in the wings which effectively reduces the structure of the line profile. In comparing the results presented with various experiments in the high electron density regime we observe the following facts. For the experiment of Elton and Griem [17] (Ly- $\left.\alpha, n_{e}=3.6 \times 10^{17} \mathrm{~cm}^{-3}, T_{e}=20400 \mathrm{~K}\right)$ the correction from time ordering improves agreement between the theoretical profile and the experimental data, while in case of the measurements of Boldt and Cooper [18] (Ly- $\alpha, n_{e}=8.4 \times 10^{16} \mathrm{~cm}^{-3}, T_{e}$ $=12200 \mathrm{~K}$ ) the agreement becomes worse. We also recall that in the $S$-matrix limit it was found $[6,19]$ for Ly- $\alpha$, as well as $H_{\alpha}$, that the strong collision parameter is enlarged due to the effects of time ordering. In view of these results it is therefore reasonable to expect that also in the case of the recent measurements by Wiese, Kelleher, and Paquette [20] $H_{\beta}$ and $H_{\gamma}, n_{f}=8.0 \times 10^{16} \mathrm{~cm}^{-3}$ $T_{e}=12700 \mathrm{~K}$ ), which at the moment may be regarded as among the best Stark broadening measurements in the high electron density region, the correction due to time ordering improves the agreement between the theoretical and experimental profiles. (For more details see also Vidal, Cooper, and Smith [21].)

The authors would like to thank Dr. D. N. Stacey for providing the predictor-corrector subroutine used to solve the differential equations.

\section{References}

[1] Griem, H. R., Kolb, A. C., and Shen, K. Y., Phys. Rev. 116, 4. (1959).

[2] Baranger, M., Phys. Rev. 111, 481 (1958).

[3] Shen, K. Y., and Cooper, J., Astrophysical Journal 155, 37 (1969).

[4] Smith, E. W., Cooper, J., and Vidal, C. R., Phys. Rev. 185, 140 (1969).

[5] Vidal, C. R., Cooper, J., and Smith, E. W., JQSRT, 10, 1011 (1970).

[6] Bacon, M., Shen, K. Y., and Cooper, J., Phys. Rev. 188, 50 (1969).

[7] Smith, E. W., Vidal, C. R., and Cooper, J., J. Res. Nat. Bur. Stand. (U.S.) 73A (Phys. and Chem.) No. 4, 389-404 (July-Aug. 1969).

[8] Smith, E. W., Vidal, C. R., and Cooper, J., J. Res. Nat. Bur. Stand. (U.S.) 73A (Phys, and Chem.) No. 4, 405-420 (July-Aug. 1969).

[9] Hooper, C. F., Phys. Rev. 165, 215 (1968).

[10] Hooper, C. F., Phys. Rev. 169, 193 (1968).

[11] Van Regemorter, H., Comptes Rendus 259, 3979 (1964).

[12] Hughes, J. W. B., Proc. Phys. Soc. 91, 810 (1967).

[13] Rose, M. E., Elementary Theory of Angular Momentum (John Wiley and Sons, New York, 1957).

[14] Gottfried, K., Quantum Mechanics, (Benjamin, Inc., New York, 1966).

[15] Berman, P. R., and Lamb, W. E., Phys. Rev. 187, 187 (1969).

[16] Wilcox, R. M., J. Math. Phys. 8, 962 (1967).

[17] Elton, R. C., and Griem, H. R., Phys. Rev. 135, Al550 (1964).

[18] Boldt, G., and Cooper, W. S., Z. Naturforschung, 19a, 968 (1964).

[19] Bacon, M., to be published.

[20] Wiese, W. L., Kelleher, D. E., and Paquette, D. R., to be published.

[21] Vidal, C. R., Cooper, J., and Smith, E. W., JQSRT, 11, 263 (1971).

[22] Hamming, R. W., J. Assoc. Comp. Mach. 6, 37 (1959). 


\section{Appendix A}

The time-consuming portion of the calculation involved obtaining the time-ordered timedevelopment operator in the intermediate $(.3 \pi<\rho \leq 10 \lambda)$ region where numerical solution of the differential equations was required. In order to efficiently solve these equations a predictorcorrector method known as Hamming's method was used [22]. The advantage of this method is that the value of the function and its derivative at the point in question are obtained in two steps rather than by an iterative process. The form of the differential equation solved is given as

$$
\frac{d y}{d x}=f(x, y)
$$

The basic equations utilized in the method are given as

Predictor:

$$
\begin{aligned}
& p_{n+1}=y_{n-3}+\frac{4 h}{3}\left(2 y^{\prime}{ }_{n}-y^{\prime}{ }_{n-1}+2 y^{\prime}{ }_{n-2}\right) \\
& m_{n+1}=p_{n+1}-\frac{112}{121}\left(p_{n}-c_{n}\right)
\end{aligned}
$$

Modifier:

$$
m^{\prime}{ }_{n+1}=f\left(x_{n+1}, m_{n+1}\right)
$$

Corrector:

$$
c_{n+1}=\frac{1}{8}\left(9 y_{n}-y_{n-2}+3 h\left(m^{\prime}{ }_{n+1}+2 y^{\prime}{ }_{n}-2 y^{\prime}{ }_{n-1}\right)\right)
$$

Final Value: $\quad y_{n+1}=c_{n+1}+\frac{9}{121}\left(p_{n+1}-c_{n+1}\right)$.

Here $p_{n+1}$ is the predicted value at the point $n+1$ in terms of the value of the function, $y$, and its first derivative, $y^{\prime}$, at the preceding four points, $m_{n+1}$ is a modification of the predicted value by taking into consideration an estimation of the truncation error (avoiding an iterative type calculation), $m^{\prime}{ }_{n+1}$ is an estimate of the first derivative based on the modified predictor, $c_{n+1}$ is a correction term which must be applied to $p_{n+1}$ to obtain the final result, $y_{n+1}$. In the above equations, $h$ is the step size and is determined by the desired accuracy of the calculation. A variable step size was used which insured the calculation remained within the specified accuracy. As these formulas are not self-starting (the first four values for $y$ are needed any time $h$ changes) it was necessary to use a Runge-Kutta procedure to obtain these initial values. 
Latest developments in the subject area of this publication, as well as in other areas where the National Bureau of Standards is active, are reported in the NBS Technical News Bulletin. See following page. 


\section{HOW TO KEEP ABREAST OF NBS ACTIVITIES}

Your purchase of this publication indicates an interest in the research, development, technology, or service activities of the National Bureau of Standards.

The best source of current awareness in your specific area, as well as in other NBS programs of possible interest, is the TECHNICAL NEWS BULLETIN, a monthly magazine designed for engineers, chemists, physicists, research and product development managers, librarians, and company executives.

If you do not now receive the TECHNICAL NEWS BULLETIN and would like to subscribe, and/or to review some recent issues, please fill out and return the form below.

Mail to: Office of Technical Information and Publications National Bureau of Standards

Washington, D. C. 20234

Name

Affiliation

Address

City State Zip

Please send complimentary past issues of the Technical News Bulletin.

Please enter my 1-yr subscription. Enclosed is my check or money order for $\$ 3.00$ (additional $\$ 1.00$ for foreign mailing). check is made payable to: SUPERINTENDENT OF DOCUMENTS. Monogr. 121 
FORM NBS.114A (1.71)

\begin{tabular}{|c|c|c|c|}
\hline \begin{tabular}{c|l} 
U.S. DEPT. OF COMM. & 1. PUBLICATION OR REPORT NO. \\
BIBLIOGRAPHIC DATA & NBS MONOgraph 121 \\
SHEET
\end{tabular} & $\begin{array}{l}\text { 2. Gov't Accession } \\
\text { No. }\end{array}$ & \multicolumn{2}{|c|}{ 3. Recipient's Accession No. } \\
\hline \multirow{2}{*}{\multicolumn{2}{|c|}{$\begin{array}{l}\text { 4. TITLE AND SUBTITLE } \\
\text { The Effect of Time Ordering on the Lyman } \propto \text { Profile }\end{array}$}} & \multicolumn{2}{|c|}{$\begin{array}{l}\text { 5. Publication Date } \\
\text { June } 1971 \\
\end{array}$} \\
\hline & & \multicolumn{2}{|c|}{ 6. Performing Organization Code } \\
\hline $\begin{array}{l}\text { 7. AuTHOR(S) } \\
\text { J. T. Godfrey, C. R. Vidal, E. W. Smith } 8\end{array}$ & Cooper & 8. Perfor & Organization \\
\hline \multirow{2}{*}{\multicolumn{2}{|c|}{$\begin{array}{l}\text { 9. PERF ORMING ORGANIZATION NAME AND ADDRESS } \\
\qquad \begin{array}{l}\text { NATIONAL BUREAU OF STANDARDS } \\
\text { DEPARTMENT OF COMMERCE } \\
\text { WASHINGTON, D.C. } 20234\end{array}\end{array}$}} & \multicolumn{2}{|c|}{$\begin{array}{l}\text { 10. Project/Task/Work Unit No. } \\
2710161\end{array}$} \\
\hline & & \multicolumn{2}{|c|}{ 11. Contract/Grant No. } \\
\hline \multirow{2}{*}{\multicolumn{2}{|c|}{ 12. Sponsoring Organization Name and Address }} & \multicolumn{2}{|c|}{$\begin{array}{l}\text { 13. Type of Report \& Period } \\
\text { Covered } \\
\text { Final }(9 / 69-9 / 70)\end{array}$} \\
\hline & & \multicolumn{2}{|c|}{ 14. Sponsoring Agency Code } \\
\hline \multicolumn{4}{|l|}{ 15. SUPPLEMENTARY NOTES } \\
\hline \multicolumn{4}{|c|}{$\begin{array}{l}\text { 16. ABSTRACT (A 200-word or less factual summaty of most significant information. If document includes a significant } \\
\text { bibliography or literature survey, mention it here.) } \\
\text { Using a unified theory of spectral line broadening previously developed, the } \\
\text { effects of time-ordering over the complete line profile are investigated. The be- } \\
\text { havior of the time-ordered thermal average and un-time-ordered thermal average } \\
\text { is obtained analytically. Calculations for the line profile of the Lyman- } 1 \text { line of } \\
\text { hydrogen are presented and are representative in that the full thermal average is } \\
\text { replaced by the thermal average with the electron velocity distribution approximated } \\
\text { by } f(v)=0(v-v) \text { where } v \text { is the thermal velocity for the plasma in question. }\end{array}$} \\
\hline \multicolumn{4}{|c|}{$\begin{array}{l}\text { 17. KEY WORDS (Alphabetical order, separated by semicolons) } \\
\text { Lyman- } \alpha \text {; Stark-broadening; time-ordering; unified theory. }\end{array}$} \\
\hline \multicolumn{4}{|c|}{$\begin{array}{l}\text { 18. AVAILABILITY STATEMENT } \\
\begin{array}{|l|l}\mathbf{x} \text { UNLIMIT ED. } & \begin{array}{l}\text { 19. SECURITY CLASS } \\
\text { (THIS REPORT) }\end{array} \\
\end{array} \\
\end{array}$} \\
\hline $\begin{array}{l}\text { FOR OFFICIAL DISTRIBUTION. DO NOT RELEASE } \\
\text { TO NTIS. }\end{array}$ & $\begin{array}{l}\text { 20. SECUR I } \\
\text { (THIS P } \\
\mathrm{X} \text { UNCLAS }\end{array}$ & $\begin{array}{l}\text { CLASS } \\
\text { GE) } \\
\text { IFIED }\end{array}$ & $\begin{array}{l}\text { 22. Price } \\
30 \mathrm{CNTS}\end{array}$ \\
\hline
\end{tabular}





\section{PERIODICALS}

JOURNAL OF RESEARCH reports National Bureaul of Standards research and derelopment in physsics, mathenatics, chenistry, and engineering. Compreliensive scientific papers give complete details of the work. including laboratory data, experimental procedures, and theoretical and minthenratical analyses. Illustrated with plotographs, drawings, and charts.

Published in three sections, available se parately:

\section{Physics and Chemistry}

Papers of interest primarily to scientists working in these fields. This section covers a broad range of physical and chemical research, with major emphasis on standards of physical measurement, fundamental constants, and properties of matter. Issued six times a year. Annual subscription: Domestic, $\$ 9.50$; foreign, $\$ 11.73^{*}$.

\section{Mathematical Sciences}

Studies and compilations designed mainly for the mathematician and theoretical physicist. Topics in mathematical statistics, theory of experiment design, numerical analysis, theoretical physics and chemistry, logical design and programming of computers and computer systems. Short numerical tables. Issued quarterly. Annual subscription: Domestic, $\$ 5.00$; foreign, $\$ 6.25 *$.

\section{- Engineering and Instrumentation}

Reporting results of interest chicfly to the engineer and the applied scientist. This section includes many of the new developments in instrumentation resulting from the Bureau's work in physical measurement, data processing, and derelopment of test methods. It will also cover some of the work in acoustics, applied mechanics, building research, and cryogenic engineering. Issued quarterly. Annual subscription: Domestic, $\$ 5.00$; foreign, $\$ 6.25^{*}$.

\section{TECHNICAL NEWS BULLETIN}

The best single source of information concerning the Bureau's research, developmental, cooperative and publication activities, this monthly publication is designed for the industry-oriented individual whose daily work involves intimate contact with science and technology-for engineers, chemists, physicists, research managers, product-development managers, and company executives. Annual subscription: Domestic, $\$ 3.00$; foreign, $\$ 4.00^{*}$.

- Difference in price is due to extra cost of foreign mailing.
NONPERIODICALS

Applied Mathematics Series. Mathernatical tables, manuals, and studies.

Building Science Series. Research results, test 111ethods, and performance criteria of building materials, components, systems, and structures.

Handbooks. Recommended codes of engineering and industrial practice (including safety codes) developed in cooperation with interested industries, professional organizations, and regulatory bodies.

Special Publications. Proceedings of NBS conferences, bibliographies, annual reports, wall charts, pamphlets, etc.

Monographs. Major contributions to the technical literature on various subjects related to the Bureau's scientific and technical activities.

National Standard Reference Data Series. NSRDS provides quantitative data on the physical and chemical properties of materials, compiled from the world's literature and critically evaluated.

Product Standards. Provide requirements for sizes, types, quality and methods for testing various industrial products. These standards are developed cooperatively with interested Government and industry groups and provide the basis for common understanding of product characteristics for both buvers and sellers. Their use is voluntary.

Technical Notes. This series consists of communications and reports (covering both other agency and NBS-sponsored work) of limited or transitory interest.

Federal Information Processing Standards Publications. This series is the official publication within the Federal Government for information on standards adopted and promulgated under the Public Law 89-306, and Bureau of the Budget Circular A-86 entitled, Standardization of Data Elements and Codes in Data Systems.

Consumer Information Series. Practical information, based on NBS research and experience, covering areas of interest to the consumer. Easily understandable language and illustrations provide useful background knowledge for shopping in today's technological marketplace.

NBS Special Publication 305, Supplement 1, Publications of the NBS, 1968-1969. When ordering, include Catalog No. C13.10:305. Price \$4.50; foreign, $\$ 5.75$.

Order NBS publications from:

Superintendent of Docuinents Government Printing Office WVashington, D.C. 20402 
U.S. DEPARTMENT OF COMMERCE

WASHINGTON, D.C. 20230

OFFICIAL BUSINESS

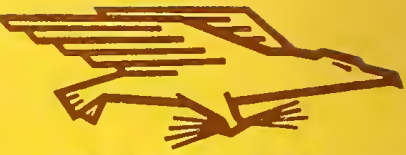

POSTAGE AND FEES PAID

U.S. DEPARTMENT OF COMMERCE

PENALTY FOR PRIVATE USE, $\$ 300$ 